\title{
Mother-Child Conflict in the Toddler Years: Lessons in Emotion, Morality, and Relationships
}

\author{
Deborah J. Laible and Ross A. Thompson
}

\begin{abstract}
Sixty-three mother-toddler dyads took part in a 6-month prospective study that examined how differences in the frequency and nature of early mother-toddler conflict related to individual differences in children's subsequent socioemotional development. When the children were 30 months, mothers and children participated in a series of laboratory tasks and in a 1.5-hr unstructured home observation. All episodes of verbal conflict between mothers and their children were identified from these sessions, transcribed, and coded for certain elements (e.g., strategy, discussion of emotion, and resolution). At 36 months, children participated in measures of emotional understanding, social competence, and early conscience development. Mothers' use of justification, resolution, and mitigation in conflict at 30 months predicted high levels of socioemotional development at age 3. These findings suggest that conflict may be an important context for children's socioemotional development.
\end{abstract}

\section{INTRODUCTION}

Recently, researchers have speculated that conflict might be an important arena for children's socialization (e.g., Dunn \& Slomkowski, 1992; Kuczynski, Kochanska, Radke-Yarrow, \& Girnius-Brown, 1987). Despite this intriguing idea, only a few empirical studies have examined how parent-child conflict might contribute to children's socioemotional development. The preliminary work that has been done supports the idea that conflict might be an important arena in which children construct social understandings (see, e.g., Herrerra \& Dunn, 1997) and valid reasons exist to suspect that it might also be an important arena in which emotional and moral understandings are also constructed (Dunn \& Slomkowski, 1992). Thus, the goal of the current study was to explore this issue by examining how maternal verbal behavior in motherchild conflict at 30 months contributed to individual differences in children's socioemotional development at age 3 .

It is hardly surprising that there is an increase in parent-child conflict throughout the toddler years; at the very time children begin to be capable of asserting their own will, parents begin to assert control over their behavior. This increase in parent-child conflict across the toddler and early preschool years is well documented by researchers (e.g., Dunn, 1988; Dunn \& Munn, 1985, 1987; Kuczynski et al., 1987). In a review of the literature on conflict, Dix (1991) suggested that parents with young children are engaged in conflict with them on average between 3.5 to 15 times an hour (although others, e.g., Klimes-Dougan \& Kopp, 1999, have reported even higher rates of conflict). However, it is important to note that not all conflict between parents and their young children surrounds issues of socialization (Dunn, 1988; Eisenberg, 1992). In fact, to view conflict solely in terms of child noncompliance or parental discipline would be to neglect the diversity of daily conflict in the lives of parents and children of this age. In addition to child noncompliance, disagreements between young children and their mothers frequently surround attitudinal or factual assertions, as well as parents' failure to comply with children's requests (Eisenberg, 1992).

Despite the fact that parent-child conflict during the toddler and preschool years is both normative and frequent, until recently there has been little explicit discussion in the literature on the role that conflict might play in children's socioemotional development (Eisenberg, 1992). Conflict, especially extreme conflict, was generally considered the marker of dysfunctional relationships. However, in recent discussions of conflict, researchers (Hartup \& Laursen, 1993; Vandell \& Bailey, 1992) have suggested that it is important to make the distinction between constructive and destructive conflicts. Thus, constructive conflict (i.e., conflict that involves high levels of negotiation, justification, and resolution) is likely to be developmentally enhancing, whereas destructive conflict is a marker of dysfunctional relationships.

A resurgence of interest in Vygotskian theory has helped to promote the idea that verbal conflict may play a significant role in children's social-cognitive development. According to Vygotsky (1978) and recent reformulations of his theory (Rogoff, 1990), children construct mental representations of their social world out of these early interactions with caregivers,

(C) 2002 by the Society for Research in Child Development, Inc. All rights reserved. 0009-3920/2002/7304-0014 
of which, as previously mentioned, conflict is a large part. This process, however, is one of co-construction in which both the parents and children create shared meaning out of their mutual interactions including conflict (Rogoff, 1990). Language plays an important role in this process because according to Vygotsky, shared discourse and interactions with older, more experienced individuals become "intramental." Therefore, the messages and meanings co-constructed by children and parents out of these early conflicts are likely to be appropriated by the children, because they are constructed within the context of a significant emotional relationship.

Similarly, emotion theorists, capitalizing on Vygotsky's ideas, have speculated that children do not develop an understanding of emotions and emotional experiences based solely on their individual experiences with emotions. Rather children construct an understanding of emotions within the context of social relationships with other people, particularly caregivers (Brown \& Dunn, 1996; Laible \& Thompson, 1998; Thompson, 1998). Thus, because conflict is a large part of these early relationships with caregivers and because conflict typically involves children's experiences with, observations of, and expressions of emotion (particularly, although not limited to, negative emotions), conflict is likely an important context in which emotional understanding is constructed (Dunn, 1988).

Likewise, maternal behavior during conflict likely impacts children's development of emotional understanding. Researchers have found links between preschool children's emotional understanding and their mothers' expressions of emotion, as well as their mothers' positive and negative responses to the children's own expressions of emotion (Denham, Zoller, \& Couchoud 1994). In addition, the frequency with which mothers discuss emotions (and causality) with children has been linked with children's subsequent use of emotional language and their subsequent levels of emotional understanding (Brown \& Dunn, 1996; Denham \& Auerbach, 1995; Dunn, Brown, \& Beardsall, 1991; Howe, 1990). Thus, whether mothers choose to discuss emotion during conflict, openly express emotion during conflict, and respond to their children's expression of emotion during conflict, likely impacts children's subsequent development of emotional understanding.

Furthermore, the quality of maternal discourse during conflict (in addition to the frequency of emotionrelated discussion) is also likely to be important in influencing children's level of emotional understanding. Although researchers have not yet examined how the quality of mother-child discourse impacts emo- tional understanding, research has suggested that the quality of maternal discourse affects other aspects of social-cognitive development, particularly autobiographical memory. This research suggests that children whose mothers use an elaborative narrative style when discussing the past have a more comprehensive representation and richer understanding of their past experiences (Fivush \& Fromhoff, 1988; Hudson, 1990; Reese, Haden, \& Fivush, 1993), suggesting that the quality of maternal discourse with children impacts children's developing memories of personal experiences.

Drawing on the work on mother-child discourse and autobiographical memory, it seems plausible to expect that the quality of maternal discourse during conflict (especially the use of explanations and justification) impacts children's understanding of their mothers' perspective and of the issues raised in conflict. Thus, mothers who provide high levels of justification (in addition to frequent discussion of emotion) during conflict are likely to have children who show more advanced levels of perspective taking, and thus, emotional understanding. In contrast, mothers who provide little explanation in conflict are not likely to provide opportunities for the growth of their children's perspective taking and thus are likely to have children who show lower levels of affective perspective taking, or emotional understanding.

Furthermore, because conflict frequently centers on issues of children's misbehavior, as well as on moral, social, and family rules (Dunn, 1988; Dunn \& Munn, 1985, 1987), conflict also likely provides a rich context for children's early conscience development. As a result, the tactics parents use to justify their side of the argument in these early conflicts are likely to have consequences for children's early conscience development. Research on parenting suggests that parents who use "other-oriented induction" (i.e., discussing the effects of their children's actions on others) in discipline encounters (typically in the context of conflict over children's noncompliance) are most likely to have children who internalize their values (Hoffman, 1984). In addition, research has also linked the discussion of emotion (when discussing children's misbehavior) with children's level of internalization (Laible \& Thompson, 2000) and early conscience development. Thus, the use of clear and extensive explanations (i.e., justification) by parents in conflicts concerning rules and moral issues, coupled with the discussion of emotion, is likely to facilitate children's early conscience development.

In contrast, simple insistence and the use of powerassertive techniques by parents in conflicts with their children are likely to discourage children's internal- 
ization of parental values, not only because of the arousal that such techniques create, but also because they discourage children's reflection on issues raised in conflict. Forceful discipline techniques (including simple insistence without explanation) elicit high levels of arousal and anxiety in children, and, according to Hoffman (e.g., 1983), this arousal interferes with children's processing of the parental message. Thus, if children are forced to comply during conflict, they are more likely to attribute compliance to their parents' use of power, rather than to internal factors, like shared values and belief systems (Hoffman, 1983).

It also seems probable that children learn how to argue effectively in these early conflicts with parents. The work of Hildy Ross and colleagues on parental intervention in sibling conflicts supports this idea (Perlman \& Ross, 1997; Ross et al., 1996) and suggests that children might model parental conflict strategies. Perlman and Ross (1997) found that children were more likely to use similar (and more advanced) conflict strategies in sibling conflict immediately following parental intervention in conflict. In addition, parents were more likely to intervene in sibling conflicts that involved physical or verbal power and were likely to intervene using sophisticated strategies (i.e., elaboration, justification, or other-oriented reasoning). Ross's work suggests that parents are using sophisticated strategies (and discussing justice) when intervening in sibling conflicts (Perlman \& Ross, 1997; Ross et al., 1997). Thus, it seems probable that parents use similar advanced strategies in their own conflicts with children and children learn from parents' effective conflict strategies.

Finally, attachment theorists have argued that children are constructing mental representations of relationships (or internal working models) out of these early interactions with caregivers that influence their perceptions of relationships (Bowlby, 1980; Bretherton, 1990; Thompson, 1997). Because conflict is a large part of the attachment relationship during the toddler years (Cicchetti, Cummings, Greenberg, \& Marvin, 1990), it seems plausible to argue that the strategies that parents use and the messages that parents convey during conflict influence children's developing representations of relationships (particularly relationships with the parents). Thus, parents' willingness and ability to negotiate, compromise, and resolve conflict with their children, as well as to actively acknowledge their children's feelings in conflict, become of paramount importance in promoting children's construction of prosocial models of relationships. In parent-child dyads in which shared plans and perspectives are not constructed in conflict, but imposed by the parents (without explanation), children are more likely to construct negative (or aggressive) models of relationships.

\section{Overview of the Current Study}

The research reported in this article was a 6-month prospective study designed to examine the issues outlined above and to explore how differences in the nature of mother-child conflict during the later half of the toddler period relate to individual differences in children's subsequent social, emotional, and early conscience development. In addition, the study examined whether children were learning or modeling conflict strategies and discourse from mothers.

Conflict assessments were taken when children were 30 months of age-at a time when their social, emotional, and moral skills are beginning to develop rapidly. For the 30-month assessments, mothers and their children participated in a series of structured videotaped laboratory tasks designed to provide a context for conflict between the mothers and children, including a free play and cleanup, a snack, a frustration paradigm, and a conversation about the children's past good behavior and misbehavior. In addition, within 2 weeks of the laboratory observation, mothers and their children also participated in a 1.5-hr unstructured audiotaped home observation. Both a laboratory and home visit were planned to allow for the ability to assess the impact of conflict across multiple contexts. The unstructured home observation was designed to allow for a wide variety of conflicts under more naturalistic conditions. The laboratory conflict was designed to provide a context for conflict over moral issues (e.g., children complying with their mothers during a cleanup task, mothers discussing children's misbehavior, and children staying away from forbidden objects).

Follow-up assessments that measured children's socioemotional and sociomoral development were taken at age 3-a time at which many of these skills begin to first crystallize-to assess the impact of conflict on these developing skills. Children's socioemotional skills were measured in a series of structured videotaped laboratory assessments designed to assess emotional understanding, early conscience development, and conceptions of family relationships.

\section{Hypotheses}

In general, it was expected that constructive mother-child conflict would be related to children's socioemotional and sociomoral development. Thus, based on the research discussed earlier, high levels of maternal justification in conflict when children were 
30 months were expected to relate to high levels of emotional understanding and early conscience development. In addition, based on previous research, the discussion of emotion in conflict was also expected to be related to high levels of emotional understanding, early conscience development, and prosocial conceptions of relationships (Brown \& Dunn, 1996; Laible \& Thompson, 2000). Finally, because of their likely links with maternal sensitivity (and attachment security), maternal mitigation and resolution in conflict was expected to be associated with prosocial conceptions of relationships.

Furthermore, on the basis of the research on maternal intervention in sibling conflict (Perlman \& Ross, 1997), it was expected that children would model maternal conflict strategies. Thus, mothers who used frequent mitigation and justification in conflict were expected to have children who used similar strategies. Finally, gender also was considered an important predictive variable in this study, because previous research has found gender differences in emotional understanding, narrative competence, and early conscience development in children of this age, typically favoring girls (see, e.g., Brown \& Dunn, 1996; Kochanska \& Aksan, 1995; Kochanska, Aksan, \& Koenig, 1995; Oppenheim, Nir, Warren, \& Emde, 1997). Thus, it was expected that girls would score higher on measures of emotional understanding, early conscience development, and prosocial conceptions of relationships.

\section{METHOD}

\section{Participants}

Sixty-five mother-child dyads were recruited to participate in the study. Mothers were recruited when the target children were between 26 to 29 months of age using names drawn from local birth announcements and with the help of local preschools and daycare centers. To ensure retention in the study, mothers were offered small monetary payments for their participation in the 30-month assessments and slightly larger payments for their participation in the 36month follow-up. Children were given a small toy for their participation in both the 30- and 36-month assessments.

Although 65 mother-toddler dyads completed the 30-month assessments, 2 mother-child dyads dropped out of the study before the 36-month assessment (due to pregnancy and work schedules). The remaining 63 participants included 33 girls and 30 boys, and were primarily White (79\%). Children came primarily from two-parent households (88.9\%). Mothers' average age was 32.4 years $(S D=5.2$ years, range $=21-45$ years $)$ and $68.3 \%$ of the mothers had a college or advanced degree $(42.9 \%$ of the fathers had a college or advanced degree). All participants came from a mid-sized midwestern city.

\section{Time 1 Procedure, Child 30 Months}

\section{Videotaped Laboratory Session}

Each mother-child dyad took part in a series of structured tasks (described below) that were designed to provide a context for conflict over moral issues. Laboratory sessions lasted approximately $1 \mathrm{hr}$ and conflict was monitored through the four segments (free play and cleanup, conversations, snack, and frustration task). All verbal conflict episodes were transcribed verbatim from the videotapes. Throughout the entire laboratory paradigm, mothers and their children were in a laboratory playroom that included a low shelf containing toys considered to be attractive to children of this age. The toys on the shelf included a pop-up Sesame Street ${ }^{\mathrm{TM}}$ toy, several stuffed animals, colorful plastic safari animals, a Winnie-the-Pooh ${ }^{\mathrm{TM}}$ western figurine set, a train set, and Sesame Street characters in racecars. Mothers were asked at the start of the laboratory paradigm to prohibit their children from touching and playing with toys on the attractive toy shelf. Mothers were instructed to correct their children's behavior toward the attractive but forbidden toy shelf in any way they felt comfortable, but to behave as they would at home when trying to prevent their children from touching something forbidden.

Free play and cleanup. Each mother-child dyad was brought into a laboratory playroom and given a 15min period of free play with attractive toys scattered about the playroom. At the end of the $15 \mathrm{~min}$, the experimenter returned briefly to ask the mother to instruct the child to place all of the toys away in eight baskets, containers, or bags. Each mother was given 15 min to accomplish this task; however, if the mother and child finished before the researcher returned, the mother was asked to retrieve the experimenter from an adjoining room.

The free play was designed primarily to allow the mother-child dyads to become comfortable in the laboratory, but was also monitored for conflict, because mothers and children sometimes engaged in friendly opposition over issues of pretend play and assertions. In contrast, the cleanup task was designed to enhance the possibility of conflict in the dyads, especially over issues of children's noncompliance (Kochanska, 1996).

Parent-child conversations about children's past behavior. Following a procedure similar to that used by 
Laible and Thompson (2000), mothers were asked to discuss with their toddlers two incidents that occurred approximately within the last week. Each mother was asked to think about two incidents that happened in the past week involving both herself and her child-one in which her child behaved well and one in which her child misbehaved. Once the events were selected, the mother was asked to sit comfortably with her child and attempt to elicit the child's memory about the event in as natural a way as possible. The length of the interview was determined by the mother who notified the researcher when the conversation ended. Conversations about children's past misbehavior typically yield frequent conflict between mothers and their children, usually over intentions and assertions (as evidenced in Laible \& Thompson, 2000). Therefore, in the present study these conversations were designed to provide a forum for conflict, especially over children's past misbehavior.

Snack. To break up a rather lengthy laboratory session, a brief snack was included that was also monitored for conflict.

Frustration paradigm. For the last 10 min of the laboratory session, mothers were asked to complete a distracter questionnaire while seated in a chair in the laboratory playroom. While children waited for their mothers to complete the questionnaire, they were given a puzzle that was too difficult to complete. The age-inappropriate puzzle was intended to enhance the desirability of the forbidden shelf to the children and increase the likelihood of conflict in the dyads.

\section{Audiotaped Home Observation}

Each mother-child dyad also took part in a 1.5-hr audiorecorded naturalistic home observation. The observation took place at a time of reported frequent mother-child conflict: prior to and during dinner (Grieshaber, 1997). Because Dunn and Munn (1985) suggested that videotaping is often too intrusive for families, interactions were audiotaped rather than videotaped. Furthermore, to reduce the obtrusiveness of having an observer present, a tape recorder was dropped off with the mothers $1 \mathrm{hr}$ before dinner. Mothers were instructed on the use of the recorder and asked to begin recording $30 \mathrm{~min}$ before dinner and to let the recorder run until the tape ended. Mothers were asked to stay in the presence of the target children as much as possible during the audiorecording and to keep the recorder nearby. To ensure that the audiorecording was clear, mothers were asked to remain indoors with the target children during all of the taping and, if possible, limit the dyad's movements during the audiorecording. Mothers were in- formed that the experimenter wished to study typical family interaction and to carry out their usual routines during the observations.

\section{Time 1 Measures, Child 30 months}

\section{Identification of All Conflict Episodes}

From the laboratory tasks described above, conflict episodes were identified, transcribed, and coded for the presence of certain elements. Conflict episodes were defined unilaterally (Hay, 1984) as the first oppositional verbal turn. Thus, coding teams examined each videotape and audiotape for all verbal oppositional statements by either the mother or the child, including verbal denials, objections, refusals, conflicting claims, disagreements, and contradictions in response to the other. Following Eisenberg (1992), conflict episodes included the initial opposition and all following conversational turns until either one party submitted, a consensus was reached, the topic of conversation was switched, or silence lasted longer than $30 \mathrm{~s}$. Conversational turns included all statements made by one speaker prior to the other partner's response. All transcripts were checked for accuracy by a second transcribing team, and disagreements were resolved through consensus.

For 15 audiotapes and 15 videotapes, conflict episodes were identified by two independent coders to assess the reliability of the identification of conflict episodes; all discrepancies were resolved by consensus. Coders agreed on the presence of a particular conflict episode $80.5 \%$ of the time and on the number of conversational turns per conflict episode $86.2 \%$ of the time in the transcripts made from the audiotaped home sessions. Similarly, coders agreed $84.6 \%$ of the time on the presence of a particular conflict episode and $87.0 \%$ on the number of conversational turns per conflict episode in the transcripts made from the videotaped laboratory sessions.

\section{Coding of Transcripts}

From the transcripts made from the video- and audiotapes, the number of conflict episodes per transcript and conflict conversational turns per speaker were tallied. Because the laboratory sessions varied in length, the total number of conflict episodes from these transcripts was corrected for by the length of each laboratory session. All other coded references were corrected for by the number of conflict conversational turns.

All conflict episodes from both sets of transcripts (i.e., the home and laboratory sessions) were coded 
for particular references, conflict strategies, and resolution following the procedures described below. Twenty transcripts from both the home and laboratory sessions were recoded by a second set of coders to establish the reliability of the coding. All disagreements among coders were resolved by consensus.

\section{References to Needs, Emotions, Moral Evaluatives, Consequences, and Rules}

All references to the following were identified and coded in conflict episodes (see Table 1 for descriptions and percentage agreement between the two coders): needs/intentions/desires, emotions, moral evaluative statements, material consequences of actions, and social / moral/family rules, (adapted from Dunn \& Munn, 1987; see also Laible \& Thompson, 2000). More than one reference was coded per conversational turn if a conversational turn contained multiple references. For each speaker, the total number of references was calculated and then divided by the total number of conflict conversational turns of that speaker. Thus, for both mothers and children, a score was calculated that represented the proportion of conflict conversational turns involving references to needs, emotions, moral evaluatives, material consequences of actions, and rules. Cohen's $\kappa$ for maternal references was .90 in the home and .88 in the laboratory. Cohen's $\mathrm{k}$ for child references was .89 in the home and .85 in the laboratory. Child references to rules during the home conflict and emotions during the home visit occurred infrequently and had zero variance. Thus, these variables were not included in any analyses.

\section{Conflict Strategy}

In addition, in the conflict episode, each conversational turn was coded as involving one of the following strategies (see Table 1 for descriptions and reliabilities): mitigation, justification, aggravation, and other (Herrera \& Dunn, 1997). Following procedures described by Herrera and Dunn, conversational turns that involved more than one strategy were coded as the strategy that reflected the highest social-cognitive level (see Table 1 for hierarchical order). Final scores were calculated for each strategy based on proportion of total number of conflict conversational turns containing each strategy for each partner (i.e., the mother and the child). Cohen's $\kappa$ for maternal conflict strategies was .83 in the home and .86 in the laboratory. Cohen's $\kappa$ for child conflict strategies was .87 for both the home and laboratory conflicts.

For both mothers and children, justification and aggravation were highly negatively correlated, $r \mathrm{~s}>$ -.75 . Thus, a composite score of these two variables was created for each speaker for the multivariate

\section{Table 1 Particular References and Conflict Strategies}

References to emotions, rules, consequences, and moral evaluatives ${ }^{\text {a }}$

1. Needs/intentions/desires (90\% mother home, $90 \%$ mother laboratory, $96 \%$ child home, $92 \%$ child laboratory): Included all references to needs, wants, desires, or intentions.

2. Emotions ${ }^{\mathrm{b}}$ (96\% mother home, $86 \%$ mother laboratory, $80 \%$ child home): Included all references to emotions or expressions of emotions (e.g., crying).

3. Moral evaluative statements ( $93 \%$ mother home, $89 \%$ mother laboratory, $90 \%$ child home, $80 \%$ child laboratory): Included all references to moral evaluatives (e.g., "good girl," "naughty boy").

4. Consequences of actions (91\% mother home, $79 \%$ mother laboratory, $78 \%$ child home, $77 \%$ child laboratory): Included all references to the logical outcome of a person's actions (e.g., "Hitting your brother will make him cry").

5. Rules ${ }^{\mathrm{C}}(80 \%$ mother home, $90 \%$ mother laboratory, $80 \%$ child laboratory): Included all references to either a social rule (such as manners), a moral rule (e.g., do not harm others), or family rules (e.g., not eating before dinner).

Conflict strategies ${ }^{\mathrm{d}}$

1. Mitigation ( $82 \%$ mother home, $79 \%$ mother laboratory, $78 \%$ child home, $85 \%$ child laboratory): Consisted of compromise and bargaining (e.g., "I will let you have a piece of candy if you eat your dinner").

2. Justification ( $89 \%$ mother home, $87 \%$ mother laboratory, $84 \%$ child home, $86 \%$ child laboratory): Consisted of the use of clarification, reasoning, or requests for clarification (e.g., "You need to eat your dinner, so that you will not be hungry later").

3. Aggravation (76\% mother home, $84 \%$ mother laboratory, $87 \%$ child home, $84 \%$ child laboratory): Consisted of the use of threats, teasing, or simple insistence with no clarification (e.g., "Because I told you so").

4. Other (78\% mother home, $80 \%$ mother laboratory, $91 \%$ child home, $84 \%$ child laboratory): Consisted of distraction, acts of submission, and off-topic and neutral statements.

Note: Percentage agreement between the two coders appears in parentheses.

a Adapted from Dunn and Munn (1987) and Laible and Thompson (2000).

b Child references to emotions in the laboratory did not occur with enough frequency to establish accurate reliability.

${ }^{c}$ Child references to rules did not occur at all in the home.

d Adapted from Herrera and Dunn (1997). Strategies are listed from the most adaptive to the least adaptive level of reasoning. 
analyses by averaging the proportion of justification with the inverse of the proportion of aggravation. This new score represented the proportion of time in conflicts that mothers used justification and low levels of aggravation.

\section{Resolution}

Finally, following procedures developed by Herrera and Dunn (1997), each conflict was scored for resolution and for the person credited with resolving the conflict. Each conflict episode was scored as being either a successful resolution or unresolved. Conflicts were scored as resolved when a party either submitted (e.g., "yes you are right") or a compromise was offered by one party and the second party agreed to it. In all conflict episodes that were scored as resolved, the person responsible for the resolution was noted (i.e., the mother or the child). The person responsible for the resolution was defined as the one whose conversational turn was the final resolution or in cases of compromise or submissions, the person who suggested the compromise or who submitted to the desires of the other (Herrera \& Dunn, 1997). Each resolution category score was expressed as the proportion of total conflict episodes containing a particular resolution (i.e., unresolved, resolved by mother, resolved by child). Cohen's $\kappa$ for the coding of resolved versus unresolved conflicts was .84 for the home conflicts and .85 for the laboratory conflicts. Cohen's $\mathrm{k}$ for distinguishing between the person responsible for the resolution (mother or child) was .86 for the home conflicts and .85 for the laboratory conflicts.

\section{Mean Length of Utterance}

The mean length of utterance (MLU) for each child was coded from the transcripts containing the home and laboratory conflicts. The mean number of words in the child's first 100 consecutive conversational turns in the home and laboratory transcripts was calculated to serve as the MLU (Shatz \& Gelman, 1973). If the child had fewer than 100 conversational turns in the conflict transcripts from the laboratory and home sessions, conversational turns from the transcripts made from one of the laboratory tasks (i.e., the conversations about the child's good behavior and misbehavior) were also used. MLU was included as a measure to control for individual differences in the child's verbal fluency and has been used by other researchers to examine the impact of aspects of discourse on socioemotional development (e.g., Dunn et al., 1991).

\section{Time 2 Procedure, Child 36 Months}

When children were 36 months of age, mothers and children returned to the laboratory to complete the outcome measures. Mothers and children began the laboratory session by completing a 10-min free play with puzzles to allow them to become comfortable in the laboratory playroom. Mothers were then asked to leave the laboratory playroom and join the experimentor in an adjoining room. At the same time, children took part in the resistance to temptation task, the emotional understanding task, and a shortened version of the MacArthur Story Stem Battery (MSSB; see Oppenheim, Nir, et al., 1997).

\section{Outcome Measures and Procedure}

Early Conscience Development:

Behavioral Internalization

Children's behavioral internalization was assessed in a standard resistance to temptation task developed by Kochanska (1995). The laboratory playroom contained a low shelf filled with attractive toys (similar to the frustration task described in the 30-month session, but containing different toys). The toys on this attractive, but forbidden toy shelf included a Mr. Potato Head ${ }^{\mathrm{TM}}$, a Tickle-Me Big Bird ${ }^{\mathrm{TM}}$, a pinwheel, plastic safari animals, a hug-and-wiggle Winniethe-Pooh, a wind-up musical box, and several colorful plastic figurines. Following the 10-min free play, mothers were asked to join the experimenter in the room adjoining the playroom to fill out a questionnaire. Mothers were asked prior to leaving the room to forbid their children from touching any of the toys on the attractive toy shelf. Each child was given a dull sorting task to work on (i.e., sorting poker chips by color) while waiting for the mother to finish her paperwork. A closed door separated the rooms that the mother and child were in, but if the child protested about being left alone, the door was opened a crack so that the child could see the mother. The mother sat at a table with her back to the child and was asked not to intervene even if she sensed that her child was playing with the prohibited toys. Bids from the child to locate the mother were curtailed by the experimenter telling the child "Mom is busy now" and by asking the child to play alone for a few more minutes. The child was alone in the laboratory for approximately $8 \mathrm{~min}$, except for a brief time when an unfamiliar research assistant entered, greeted the child, played with the three most attractive prohibited toys (with clear enjoyment), wound up a musical toy, and left the room. If the child left the room for a period, the paradigm was extended so 
that a total of $8 \mathrm{~min}$ of the child alone in the room could be coded.

The child's behavior while alone with the forbidden toys was coded every $5 \mathrm{~s}$ from the videotapes for compliance with the maternal request in the absence of the mother. Adapting a coding scheme from Kochanska and Aksan (1995), the following behavior was coded: looking at shelf / no attempt to touch $(M=$ 17.4 coded intervals, $S D=12.1$ ), self-correction (extending hand toward the objects, but withdrawing or touching less than $3 \mathrm{~s} ; M=.28, S D=.84$ ), gentle touch (touching objects, but tentatively or gently; $M=.98, S D=2.6$ ), deviation (taking objects from shelf and playing with them; $M=13.1, S D=24.1$ ), competing activity (otherwise occupied/not looking at shelf or sorting; $M=23.3, S D=23.5$ ), and sorting $(M=40.1, S D=27.7)$. The codes were mutually exclusive and 20 tapes were recoded to establish reliability. Percentage agreement between the two coders were as follows: looking, $85 \%$; self-correction, $78 \%$; gentle touch, $91 \%$; deviation, $90 \%$; competing activity, $89 \%$; and sorting, $85 \%$. Cohen's $\kappa$ for the coding was .85 .

To reduce the number of variables, the six codes were submitted to a principal components factor analysis with varimax rotation. Two factors emerged but only one was submitted to further analyses. This factor (eigenvalue $=1.8,30 \%$ of the variance) was labeled "deviation" and consisted of deviation (.80) and gentle touch (.68), which loaded positively and sorting, which loaded negatively $(-.80)$. Following precedent by Laible and Thompson (2000), this deviation factor was reverse scored and labeled "behavioral internalization" for ease of interpretation.

\section{Emotional Understanding}

To assess their emotional understanding, children took part in a two-part affective perspective-taking task developed by Denham (1986). This measure has shown good concurrent and predictive validity in assessing emotional understanding in preschool children (see, e.g., Brown \& Dunn, 1996; Laible \& Thompson, 1998). In the first part of the task, children's ability to recognize facial expressions of emotion was assessed. Each child examined four felt faces on which the expressions of sad, happy, angry, and afraid were drawn and the researcher asked the child to pick the face that corresponded to each of the four target emotions (e.g., "show me the happy face"). Following this, each child was asked to report the emotion that each face represented (e.g., "how does this face feel?"). For both tasks, each child received 2 points for the correct identification of each emotion or 1 point for identifying a face with the correct positive-negative valence. If children misidentified any of the felt faces, at the end of the task the researcher corrected them and asked them to reidentify the emotions until it was clear that they understood which face depicted which emotion.

Following this, each child saw hand puppets enact 20 vignettes that were accompanied by vocal and visual cues by the puppet/experimenter (e.g., big smile and joyful voice by experimenter when the puppet was portrayed as happy). In 8 of the 20 stories (labeled the stereotypical stories), the puppet was shown to feel the same way most people would feel in this circumstance (e.g., fear during a nightmare). In the other 12 vignettes (labeled the nonstereotypical stories), the puppet was shown to feel the opposite way the child would feel under the same circumstance. Therefore, each of the "nonstereotypical" puppet interviews was tailored to the child's expected responses. Each mother previously filled out a forcedchoice, 12-item questionnaire (while her child completed the resistance to temptation task) that asked her to predict how the child would probably feel in each of the 12 commonplace circumstances portrayed in the nonstereotypical stories (e.g., happy versus afraid when seeing a big, but friendly dog). In each of the nonstereotypical stories, the puppet was portrayed as feeling in a manner inconsistent with how the mother reported the child would probably feel in that situation (although in a manner that was plausible given the circumstances of the story). For example, if the mother reported that her child would be happy to see a big, although friendly dog, the puppet was portrayed (vocally and visually) by the experimenter as being afraid when seeing the dog. Thus, the nonstereotypical puppet vignettes were designed to test whether children could separate their own feelings in the situation from those of the story character (i.e., the puppet) and accurately report the emotions of the story character.

At the end of each of the 20 enactments, each child was asked, "how did the puppet feel?" and was then asked to affix the proper felt face to the puppet from the four choices to indicate the puppet's feeling. A child received 2 points for each correct answer (i.e., identifying the emotion that the puppet was portrayed as feeling) or 1 point for identifying the correct positive-negative valence (e.g., picking the sad face rather than the correct angry one). The scores on each of the 20 vignettes (the 8 stereotypical and the 12 nonstereotypical) were summed and following Denham's procedures (1986), this score was added to that of the previous task (i.e., identifying the emotions on the felt faces) to serve as an index of emotional understand- 
ing. A total of 56 points was possible (in this study, $M=33.5, S D=8.90)$.

\section{Representations of Family Relationships}

To assess perceptions of family relationships, children were administered a shortened version of the MSSB (see Oppenheim, Nir, et al., 1997). The MSSB was designed to tap children's ability to produce positive outcome narratives from complex, conflictual relationship-oriented story stems and is believed to assess children's representations of relationships (Bretherton, 1990). Such skills have been linked to a wide variety of positive developmental outcomes, including emotional regulation, the ability to share personal experiences, and fewer behavioral problems (Oppenheim, Emde, \& Warren, 1997; Oppenheim, Nir, et al., 1997).

Although the MSSB involves 12 stories, due to the young age of the children in this study, only 6 stories were used. The researcher explained to each child that for this game, she would make up some stories with the dolls and that for each story, the researcher would start the story and the child could finish it. Following this, a warm-up story was presented using the dolls and the child was encouraged to manipulate the dolls. The stems were presented in a spirited, dramatic manner and all ended with the request, "Can you show me what happens next?" Nondirective prompts, for example, "Does anything else happen?" were used to assist the child's narrative. The experimenter moved to the next story stem after the child had addressed the main issue in the stem or had indicated that he or she was finished with the story.

Children's responses to the doll stories were transcribed verbatim from the videotapes. Any actions that children made with the dolls were also summarized in the transcripts (e.g., two dolls embracing). Using a system developed by the MacArthur Narrative Workgroup (see Oppenheim, Nir, et al., 1997), coders coded the transcribed narratives and two independent coders coded 20 common transcripts to establish reliability of coding. Percentage agreement between the two coders and the mean number of coded themes per transcript appear in parentheses. Cohen's $\kappa$ for the measure was .88. Overall content themes were as follows:

1. Personal injury $(85 \% ; M=.21, S D=.48)$ : A character was physically injured or hurt, and the focus was on the injury and not the aggression.

2. Aggression $(81 \% ; M=.44, S D=.69)$ : A character made hostile or destructive gestures.
3. Affection $(80 \% ; M=.25, S D=.69)$ : A character was displayed as hugging, kissing, being praised, and so forth.

4. Affiliation ( $92 \% ; M=1.89, S D=1.14)$ : Characters participated in a positive activity together.

5. Empathy/helping (88\%; $M=1.30, S D=1.12)$ : A character or the child identified with or demonstrated an understanding of the thoughts and feelings of another or helped another with a task.

6. Reparation/guilt (89\%; $M=.95, S D=.96)$ : A character made amends or displayed feelings of guilt.

7. Atypical negative responses ( $88 \% ; M=1.13, S D=$ 1.09): The child displayed disorganized or very unusual responses with a clear negative tone.

Because children often presented more than one theme sequentially in narrative, a narrative could receive more than one coded content theme. Content themes in each category were summed across all the narratives and to reduce the number of content themes. Based on conceptual similarity, two composite content themes were formed by summing themes (see Oppenheim, Nir, et al., 1997): (1) a prosocial composite including empathy/helping, reparation/guilt, affiliation, and affection $(M=4.40, S D=1.90)$; and (2) an aggressive composite including aggression, personal injury, and atypical negative responses $(M=$ $1.80, S D=1.50$ ).

In addition to content theme, the narratives were coded for coherence (again following procedures established by Oppenheim, Nir, et al., 1997) on a 10-point scale. The odd-numbered anchor points were as follows: 1 (fragmented, shifted story line), 3 (child understood conflict, but did not offer resolution; part of the story was incoherent), 5 (child understood the conflict and handled it by using simplification of the story), 7 (child understood the story and offered resolution, but the story was short with no embellishment), and 9 (child understood conflict, offered embellished resolution; there were no incoherent segments). A composite score of narrative coherence was formed by averaging the scores across narratives $(M=4.10$, $S D=1.50)$. Internal consistency for the measure was .85 , and interrater reliability using interclass correlations ranged from .79 to .88 .

\section{RESULTS}

\section{Descriptive Data on Conflict Episodes and Outcome Measures}

Descriptive data on all of the conflict episodes appears in Tables 2 and 3. The means and standard 
Table 2 Means and Standard Deviations of the Proportions of Maternal and Child References for the Home and Laboratory Sessions

\begin{tabular}{|c|c|c|c|c|c|c|}
\hline \multirow[b]{2}{*}{ Reference $^{\mathrm{a}}$} & \multicolumn{3}{|c|}{ Home Conflict } & \multicolumn{3}{|c|}{ Laboratory Conflict } \\
\hline & $M$ & $S D$ & Range & $M$ & $S D$ & Range \\
\hline Maternal references to needs/desires/intentions & .17 & .10 & $0-.50$ & .15 & .12 & $0-.67$ \\
\hline Maternal references to emotions* & .08 & .06 & $0-.33$ & .06 & .07 & $0-.31$ \\
\hline Maternal references to moral evaluatives* & .06 & .06 & $0-.27$ & .09 & .07 & $0-.32$ \\
\hline Maternal references to consequences of actions & .03 & .03 & $0-.15$ & .03 & .03 & $0-.15$ \\
\hline Maternal references to social/moral/family rules** & .02 & .03 & $0-.12$ & .06 & .08 & $0-.38$ \\
\hline Child references to needs/desires/intentions & .16 & .11 & $0-.45$ & .12 & .11 & $0-.49$ \\
\hline Child references to emotions ${ }^{* *}$ & .02 & .03 & $0-.15$ & .001 & .02 & $0-.11$ \\
\hline Child references to moral evaluatives ${ }^{* *}$ & .07 & .02 & $0-.10$ & .04 & .05 & $0-.24$ \\
\hline Child references to consequences of actions & .04 & .03 & $0-.03$ & .06 & .03 & $0-.02$ \\
\hline Child references to social/moral/family rules ${ }^{b}$ & - & - & - & .01 & .01 & $0-.10$ \\
\hline
\end{tabular}

a References were corrected by the number of conflict conversational turns of each speaker and thus represent the proportion of conversational turns containing a particular reference.

b Child references to rules in the home and emotions in the laboratory visit occurred infrequently and basically had zero variance.

* The difference between the laboratory and home conflict was significant at $p<.05$.

** The difference between the laboratory and home conflict was significant at $p<.01$.

deviations are presented separately for both the home and laboratory conflict episodes. In addition, differences between the laboratory and home conflict elements were tested with $t$ tests and those elements that significantly differed between the laboratory and home conflict episodes are noted in the tables. Mothers and children were more likely to discuss emotion and moral evaluatives during conflict at home than during conflict in the laboratory. In contrast, mothers were more likely to discuss rules during the laboratory conflict than during the home conflict. Furthermore, mothers were less likely to offer compromises (or mitigate) during the laboratory conflict than during the home conflict and children were far more likely to offer compromises during the laboratory conflict than during the home conflict. Finally, children were more likely to resolve the laboratory conflict than the home conflict.

Table 3 Means and Standard Deviations of the Proportions of Maternal and Child Conflict Strategies for the Home and Laboratory Sessions

\begin{tabular}{|c|c|c|c|c|c|c|}
\hline \multirow[b]{2}{*}{ Reference $^{\mathrm{a}}$} & \multicolumn{3}{|c|}{ Home Conflict } & \multicolumn{3}{|c|}{ Laboratory Conflict } \\
\hline & $M$ & $S D$ & Range & $M$ & $S D$ & Range \\
\hline Maternal use of justification ${ }^{b}$ & .63 & .13 & $.24-.86$ & .62 & .16 & $.27-1.0$ \\
\hline Maternal use of aggravation ${ }^{b}$ & .20 & .15 & $0-.68$ & .24 & .17 & $0-.73$ \\
\hline Maternal use of mitigation* & .07 & .05 & $0-.23$ & .05 & .05 & $0-.27$ \\
\hline Maternal use of other strategies & .03 & .03 & $0-.15$ & .08 & .07 & $0-.29$ \\
\hline Child use of justification ${ }^{c}$ & .36 & .16 & $0-.69$ & .35 & .15 & $0-.80$ \\
\hline Child use of aggravation ${ }^{c}$ & .50 & .18 & $.13-1.0$ & .47 & .18 & $.17-1.0$ \\
\hline Child use of mitigation ${ }^{* *}$ & .01 & .02 & $0-.08$ & .06 & .07 & $0-.33$ \\
\hline Child use of other strategies & .10 & .06 & $0-.24$ & .17 & .12 & $0-.55$ \\
\hline Proportion of conflicts resolved by mother & .11 & .13 & $0-1.0$ & .07 & .09 & $0-.50$ \\
\hline Proportion of conflicts resolved by child ${ }^{* *}$ & .11 & .08 & $0-.41$ & .17 & .15 & $0-.67$ \\
\hline
\end{tabular}

a Conflict strategies were corrected by the number of conversational turns of each speaker and thus represent the proportion of conversational turns (in conflict) containing a particular strategy.

${ }^{\mathrm{b}}$ Maternal justification was combined with the inverse of aggravation for all subsequent bivariate/multivariate analyses (home composite: $M=1.42, S D=.27$, range $=.56-1.80$; laboratory composite: $M=1.37, S D=.31$, range $=.55-2.00)$.

${ }^{\mathrm{c}}$ Child justification was combined with the inverse of aggravation for all subsequent bivariate/multivariate analyses (home composite: $M=.85, S D=.33$, range $=0-1.49$; laboratory composite: $M=.88, S D=.31$, range $=0-1.60)$.

* The difference between the laboratory and home conflict was significant at $p<.05$.

** The difference between the laboratory and home conflict was significant at $p<.01$. 


\section{Predicting Outcome Measures}

Overview of Regression Models

Hierarchical regression models were built to predict the social, emotional, and moral outcome measures at age 3 from the conflict assessments. Because of the large numbers of predictors, specific predictors were chosen for each model on the basis of previous research and theory. Gender and MLU were entered in the first step of all models as controls (with the exception of the model that predicted behavioral internalization in which the verbal measure MLU was not used as a control). Gender was entered because, as previously discussed, research has occasionally found gender differences in emotional understanding, narrative competence, and early conscience development in children of this age, typically favoring girls. Children's MLU was included as a measure of verbal fluency/intelligence to correct for any effect that verbal competency might have on the verbal outcome measures. In addition, maternal justification (and low aggravation), mitigation, and resolution were entered in the second step of all models. Child conflict variables were also initially examined in regression models. The addition of these variables, however, seldom increased the predictive variance in the regression models (and never made significant independent contributions to these models). Thus, to enhance power and decrease the participant to variables ratio, only maternal predictors were included in the models. These variables have been described by research and theory to be important in fostering socioemotional and sociomoral outcomes (see Dunn \& Slomkowski, 1992; Herrera \& Dunn, 1997). The inclusion of additional variables in each model was justified for specific theoretical reasons when necessary.

\section{Emotional Understanding}

The regression models that used the laboratory and home conflict episodes to predict emotional understanding appear in Table 4 . In addition to maternal mitigation, justification, and resolution, maternal references to emotions and needs were also included in the model that predicted emotional understanding. Prior research has linked both maternal discussion about feeling states (including references to needs, desires, and intentions) and causality to a child's level of emotional understanding (Brown \& Dunn, 1996; Dunn et al., 1991).

The addition of the control variables in the first step of the model (i.e., gender and MLU) significantly increased the variance accounted for in emotional understanding in both models. The addition of the
Table 4 Regression Models Predicting Emotional Understanding at Age 3 from Conflict Elements at Age 2.5 Years

\begin{tabular}{lcc}
\hline & $\begin{array}{c}\beta \text { at Final } \\
\text { StepUsing } \\
\text { Home } \\
\text { Conflict } \\
\text { Elements }\end{array}$ & $\begin{array}{c}\beta \text { at Final } \\
\text { Step Using } \\
\text { Laboratory } \\
\text { Conflict } \\
\text { Elements }\end{array}$ \\
\hline 1. Gender & .18 & .22 \\
Mean length of utterance & $.40^{* *}$ & $.41^{* *}$ \\
Multiple $R^{2}$ & $.23^{* *}$ & $.23^{* *}$ \\
$R^{2}$ change & $.23^{* *}$ & $.23^{* *}$ \\
$F$ change & $8.94^{* *}$ & $8.94^{* *}$ \\
2. Maternal mitigation & -.18 & .01 \\
Maternal justification $/$ low & & .05 \\
aggravation & $.33^{* *}$ & -.15 \\
Maternal references to emotions & .09 & -.08 \\
Maternal references to needs & $-.32^{* *}$ & -.11 \\
Maternal resolution & $.24^{*}$ & $.26^{*}$ \\
Multiple $R^{2}$ & $.47^{* *}$ & .04 \\
$R^{2}$ change & $.24^{* *}$ & .57 \\
$F$ change & $4.86^{* *}$ & \\
\hline * $p<.05 ;{ }^{* *} p<.01$. & &
\end{tabular}

conflict variables in the second step, however, only significantly increased the variance accounted for in emotional understanding in the model that used the conflict elements from the home observation. In this model, four variables (i.e., MLU, maternal justification, maternal references to needs [having a suppressor effect], and maternal resolution) made significant independent contributions to the model. High levels of verbal ability at 30 months (i.e., MLU) were associated with higher levels of emotional understanding at 36 months. In addition, mothers who used high levels of justification (and lower levels of aggravation) in home conflict and who were more likely to resolve conflicts when their children were 30 months had children who displayed high levels of emotional understanding at age 3. Finally, frequent references to needs, desires, and wants by mothers during home conflict episodes were associated with lower levels of emotional understanding.

\section{The MSSB Prosocial and Aggressive Themes} and Coherence

Regression models that predicted prosocial themes and coherence in the MSSB appear in Tables 5 and 6. In addition to maternal mitigation, justification, and resolution, maternal emotion-laden discourse variables (i.e., references to emotions and needs) were also included in the model that predicted prosocial and aggressive themes and coherence. These predictors were included because a previous study (Laible \& 
Table 5 Regression Models that Predicted Prosocial Themes in the MacArthur Story Stem Battery at Age 3 from Conflict Elements at Age 2.5 Years

\begin{tabular}{lcc}
\hline & $\begin{array}{c}\beta \text { at Final } \\
\text { Step Using } \\
\text { Home } \\
\text { Conflict } \\
\text { Elements }\end{array}$ & $\begin{array}{c}\beta \text { at Final } \\
\text { Step Using } \\
\text { Laboratory } \\
\text { Conflict } \\
\text { Elements }\end{array}$ \\
Predictor and Step & .22 & $.28^{*}$ \\
\hline 1. Gender & -.10 & .07 \\
Mean length of utterance & $.11^{*}$ & $.11^{*}$ \\
Multiple $R^{2}$ & $.11^{*}$ & $.11^{*}$ \\
$R^{2}$ change & 3.35 & 3.35 \\
F change & $.37^{* *}$ & -.04 \\
2. Maternal mitigation & & \\
Maternal justification/low & .04 & .18 \\
$\quad$ aggravation & .06 & -.19 \\
Maternal references to emotions & .08 & .04 \\
Maternal references to needs & .19 & $.27^{*}$ \\
Maternal resolution & $.28^{*}$ & $.24^{*}$ \\
Multiple $R^{2}$ & $.17^{*}$ & .13 \\
$R^{2}$ change & $2.48^{*}$ & 1.88 \\
\hline F change & & \\
\hline
\end{tabular}

${ }^{*} p<.05 ;{ }^{* *} p<.01$.

Thompson, 2000) found significant relations between attachment security and emotion-laden discourse. Thus, it seemed likely that emotion-laden maternal discourse might also be influential in children's developing representations of relationships, and by including maternal emotion-laden discourse elements in the regression models, this hypothesis could be examined.

The addition of gender and MLU to both models that predicted prosocial themes in the MSSB significantly increased the amount of variance accounted for by the models. The addition of the conflict elements in the second step of both models significantly increased the amount of variance accounted for by the model that used the home conflict predictors. In addition, the amount of variance accounted for by both of the final models was significant. In the model that predicted prosocial themes using home conflict elements, only maternal mitigation made a significant independent contribution to the model. Mothers who used more mitigation in home conflicts when the children were 30 months had children who represented more prosocial themes in the MSSB doll stories when the children were 36 months. In the model that used laboratory conflict to predict prosocial themes, only maternal resolution and gender made significant independent contributions to the model. Children whose mothers frequently resolved laboratory conflicts when they were 30 months were more likely to portray prosocial themes in the MSSB doll stories when they were 36 months than those whose mothers
Table 6 Regression Models that Predicted Coherence in the MacArthur Story Stem Battery at Age 3 from Conflict Elements at Age 2.5 Years

\begin{tabular}{lcc}
\hline & $\begin{array}{c}\beta \text { at Final } \\
\text { Step Using } \\
\text { Home } \\
\text { Conflict } \\
\text { Elements }\end{array}$ & $\begin{array}{c}\beta \text { at Final } \\
\text { Step Using } \\
\text { Laboratory } \\
\text { Conflict } \\
\text { Elements }\end{array}$ \\
\hline 1. Gender & .25 & $.29^{*}$ \\
Mean length of utterance & .07 & .17 \\
$\quad$ Multiple $R^{2}$ & $.14^{*}$ & $.14^{*}$ \\
$R^{2}$ change & $.14^{*}$ & $.14^{*}$ \\
$F$ change & $4.89^{*}$ & $4.89^{*}$ \\
2. Maternal mitigation & $.30^{*}$ & -.08 \\
Maternal justification/low & & \\
$\quad$ aggravation & .04 & .14 \\
Maternal references to emotions & .01 & -.11 \\
Maternal references to needs & .03 & -.12 \\
Maternal resolution & .19 & $.24^{*}$ \\
$\quad$ Multiple $R^{2}$ & $.24^{*}$ & $.22^{*}$ \\
$R^{2}$ change & .10 & .07 \\
$F$ change & 1.26 & 1.05 \\
\hline
\end{tabular}

${ }^{*} p<.05$.

did not. Also, girls were more likely than were boys to suggest prosocial endings to the doll narratives.

The addition of the control variables (MLU and gender) to the models that predicted coherent narratives in the MSSB significantly increased the amount of variance in both models. The addition of the subsequent variables in the second step of the models failed to significantly increase the amount of variance accounted for in both models. The overall amount of variance accounted for in both models, however, was significant. Only maternal mitigation made a significant independent contribution to the model with the home conflict elements. Maternal use of mitigation in the home conflicts was associated with higher levels of narrative coherence by children in the MSSB stories. In the model that used the laboratory conflict elements, both gender and maternal resolution made significant independent contributions to the model. Mothers who frequently resolved conflict had children who produced the most coherent narratives. In addition, girls were more likely to produce coherent narratives than were boys. The two regression models that predicted aggressive themes in the MSSB were not significant and had no significant predictors.

\section{Behavioral Internalization in the Resistance to Temptation Task}

The regression models that predicted behavioral internalization from the conflict elements appear in 
Table 7 Regression Models that Predicted Behavioral Internalization in the Resistance to Temptation Task at Age 3 from Conflict Elements at Age 2.5 Years

\begin{tabular}{lcc}
\hline & $\begin{array}{c}\beta \text { at Final } \\
\text { Step Using } \\
\text { Home } \\
\text { Conflict } \\
\text { Elements }\end{array}$ & $\begin{array}{c}\beta \text { at Final } \\
\text { Step Using } \\
\text { Laboratory } \\
\text { Conflict } \\
\text { Elements }\end{array}$ \\
\hline Predictor and Step & $.27^{*}$ & $.39^{* *}$ \\
\hline 1. Gender & $.12^{* *}$ & $.12^{* *}$ \\
Multiple $R^{2}$ & $.12^{* *}$ & $.12^{* *}$ \\
$R^{2}$ change & $8.54^{* *}$ & $8.54^{* *}$ \\
$F$ change & .15 & .09 \\
2. Maternal mitigation & & \\
Maternal justification/low & -.20 & $.35^{* *}$ \\
$\quad$ aggravation & .16 & $.35^{* *}$ \\
Maternal references to emotions & .12 & -.14 \\
Maternal references to needs & & \\
Maternal references to moral & .08 & .19 \\
$\quad$ evaluatives & -.19 & -.15 \\
Maternal references to consequences & -.10 & .07 \\
Maternal references to rules & .09 & .07 \\
Maternal resolution & .24 & $.37^{* *}$ \\
$\quad$ Multiple $R^{2}$ & .11 & $.25^{*}$ \\
$R^{2}$ change & .95 & $2.45^{*}$ \\
$\quad F$ change & &
\end{tabular}

${ }^{*} p<.05 ;{ }^{* *} p<.01$.

Table 7. In addition to maternal mitigation, justification, and resolution, maternal references to needs, emotions, moral evaluatives, consequences, and rules were also included in the models that predicted behavioral internalization in the resistance to temptation task. Previous research and theory has argued that the discussion of emotions, consequences, and rules might be important in children's early conscience development (Dunn, 1987, 1988; Laible \& Thompson, 2000).

In predicting internalization, the addition of the control variables in the first step of both models significantly increased the amount of variance accounted for in the models. The addition of the conflict elements in the second step of the models that predicted internalization significantly increased the amount of variance accounted for only in the model that used the laboratory conflict elements. In this model, gender, maternal justification (and low aggravation), and maternal references to emotions all made significant independent contributions to predicting internalization. Girls, in addition to children whose mothers used frequent justification and references to emotions in laboratory conflict, displayed the highest levels of behavioral internalization in the resistance to temptation task.
Do Maternal Conflict Strategies Predict Child Conflict Strategies?

To examine whether maternal conflict strategies predicted child conflict strategies (and discourse), bivariate relations between maternal conflict strategies/discourse and child strategies/discourse were examined. With regard to conflict strategies, there was some support for the idea that maternal strategies were related to children's use of similar strategies. Maternal justification and lack of aggravation in both laboratory and home conflicts was correlated with children's use of justification and lack of aggravation, laboratory: $r=.35, p=.004$; home: $r=.39, p=.002$. Mothers who used more justification and less aggravation in conflict had children who also used high levels of justification and low levels of aggravation. Maternal mitigation, however, was unrelated to child mitigation, regardless of conflict context.

With regard to maternal discourse, maternal references also predicted child references (however, this was context and reference specific). Maternal references to moral evaluatives were significantly correlated with child references to moral evaluatives in the laboratory conflict only, $r=.58, p=.001$. Mothers who made frequent references to moral evaluatives had children who also made such frequent references. Finally, maternal references to consequences of actions were significantly correlated with child references to consequences in the laboratory only, $r=.34, p=.007$. Mothers who made frequent references to consequences of actions in laboratory conflict had children who also made frequent references to consequences of actions. No other significant relations were found between maternal and child discourse variables.

\section{DISCUSSION}

The major goal of this study was to examine how differences in the frequency and nature of mother-child conflict at 30 months were related to individual differences in children's socioemotional and sociomoral development at 36 months. Overall, the results from the study provided partial support for the hypothesis that differences in mother-toddler conflict at 30 months contribute to individual differences in socioemotional and sociomoral functioning at 36 monthsalthough the influence of mother-toddler conflict appears to vary both by the context of the conflict (laboratory versus home) and by the outcome assessed (e.g., emotional understanding versus behavioral internalization). Conflict between toddlers and mothers in this study was frequent (occurring on average 19 times an hour), lending support to the argument that 
mother-toddler conflict is normative during this stage of a child's life (Dunn, 1988; Dunn \& Munn, 1985, 1987). Although this estimate of the frequency of conflict is higher than some researchers have found (Dix, 1991), it is entirely consistent with other estimates (see, e.g., Klimes-Dougan \& Kopp, 1991). In addition to being frequent, the mother-toddler conflict observed in this study spanned a wide range of issues, from conflicts over factual issues to more serious conflicts over aggression.

Relations among maternal and child conflict elements themselves supported the idea that children may, in fact, be modeling maternal verbal behavior in conflict episodes (Ross et al., 1997). Mothers who used high levels of justification and low levels of aggravation had children who used similar strategies in conflict. In addition, maternal references to moral evaluatives and consequences of actions in conflict were also significantly related to children's use of such references in conflict. Although it is possible that children's references to feelings, moral evaluatives, or consequences in conflict were driven by the conflict topic and maternal arguments, the longitudinal research by Dunn and colleagues (Brown \& Dunn, 1996; Dunn et al., 1991) suggests another explanation. These researchers have shown that maternal discourse about emotion early in life predicts children's subsequent use of emotional language and suggests that children are learning communication patterns from parents. Therefore, it seems likely that children acquire from these early conflicts styles of discourse that are similar to parents.

Consistent with predictions, constructive maternal behavior in conflict with children at 30 months predicted socioemotional and sociomoral competence at age 3. The most consistent predictors of high levels of socioemotional and sociomoral development at age 3 were the strategies that mothers used in conflict and maternal resolution of conflict at 30 months. High levels of maternal justification (and low levels of aggravation) and maternal resolution in home conflicts at 30 months were related to higher levels of emotional understanding at age 3 . In addition, high levels of maternal justification (and low levels of aggravation) in laboratory conflicts were associated with high levels of behavioral internalization in the resistance to temptation task.

These findings suggest that clear and extensive explanations by mothers during conflict episodes may promote children's emotional and moral understanding. Explanations by mothers (and also perhaps resolution by mothers) may be important in making children cognizant of multiple perspectives and fostering perspective taking, which is important for the growth of emotional and moral understanding (Hoffman, 1983). Previous research has found links between children's level of sociomoral development and reasoning and explanation by mothers in disciplinary encounters (e.g., Hart, Ladd, \& Burleson, 1990; ZahnWaxler, Radke-Yarrow, \& King, 1979). However, this study suggests that the benefits of reasoning and explanation on children's socioemotional development transcend disciplinary conflicts and likely encompass all types of conflict. Similarly, it seems that simple insistence by parents during conflict limits the growth of perspective taking, and, as the research on discipline suggests (e.g., Hoffman, 1984), is detrimental to children's internalized compliance and emotional understanding.

In addition, maternal mitigation and resolution were also significant predictors of children's representations of relationships (as tapped by the MSSB). Children whose mothers used high levels of mitigation in home conflicts at 30 months were most likely to show high levels of narrative coherence and most likely to provide prosocial themes in their narratives at 36 months. In addition, maternal resolution in laboratory conflicts at 30 months was significantly associated with children's production of prosocial themes at 36 months. These findings are provocative because they support the idea that children are in fact constructing models of relationships, and the kinds of skills necessary to maintain relationships, out of these early conflicts with caregivers. Mothers who were constructive in conflict (providing frequent mitigation and showing a willingness to resolve conflict) clearly had children who perceived relationships in a more prosocial and coherent manner.

The result of this study also support the importance of emotion-laden maternal discourse for fostering early socioemotional development. Consistent with other research (Laible \& Thompson, 2000), maternal discussion of emotion during conflict was important in predicting early conscience development. In the laboratory conflict (that tended to center on moral issues), mothers who more frequently discussed emotion had children who scored higher on behavioral internalization during the resistance to temptation task. Thus, as others have speculated (e.g., Dunn, 1987), emotion-laden discourse during conflict may indeed have consequences for children's early conscience development, most likely because it fosters the development of moral emotions (such as empathy and guilt).

In addition, maternal references to emotion in home conflict were significantly correlated with emotional understanding 6 months later. Despite this, maternal references to emotion were not a strong enough pre- 
dictor to hold in the regression models that predicted emotional understanding, in which there were other more substantial predictors (such as maternal justification). Although the reason that emotion-laden discourse was not a substantial predictor of emotional understanding is unclear, it is likely due to the young age of the children. The children in this study were slightly younger than those in other studies that have found links between emotion-laden discourse and children's subsequent moral and emotional understanding (e.g., Brown \& Dunn, 1996). Thus, emotionladen discourse may be more influential later in development when children have a stronger verbal understanding and have better developed the ability to label and understand emotions.

Furthermore, consistent with other research (Laible \& Thompson, 2000), the discussion of rules and consequences of actions during conflict had little impact on children's subsequent socioemotional and sociomoral development. This finding has important implications for future research on socioemotional and sociomoral development and discourse. Researchers should consider that not all forms of discourse are equally influential in fostering high levels of socioemotional and sociomoral development, and as a result, it is important to consider the particular elements of discourse that are or are not effective in fostering emotional and moral understanding.

The present study highlights the importance of examining context when considering the effects of discourse on social and emotional development. In this study, there were clear differences in the predictive value of conflict elements on the basis of conflict context. Overall, laboratory conflict elements were the most potent predictors of early conscience development, likely because of the fact that the conflict in the laboratory tended to center on issues of compliance with laboratory rules (e.g., not touching a forbidden shelf). Although the rules in the laboratory were somewhat arbitrary, they were not unrepresentative of the types of situations in which children's compliance is the primary concern (e.g., at the grocery store or at a doctor's office) and this study suggests that conflict in this context may in fact be important for the development of behavioral regulation. In contrast, the home conflict was more dynamic and representative of the kinds of topics that come up during dinnertime routines. Thus, unsurprisingly, home conflict elements were predictive of different aspects of socioemotional development (e.g., emotional understanding) and were unrelated to behavioral internalization.

Finally, gender was also a potent predictor of children's level of socioemotional and sociomoral development at age 3 , a finding that is also consistent with other research (Kochanska, 1995; Oppenheim, Nir, et al., 1997). Girls consistently scored higher than did boys on behavioral internalization. In addition, girls were more likely at age 3 to produce coherent narratives and narratives with prosocial themes during the MSSB, suggesting that they had more prosocial representations of relationships and better narrative skills than did boys. These results are consistent with recent theorizing that girls are socialized toward and display an orientation that emphasizes relationships, $\mathrm{CO}^{-}$ operation, and emotional experience (Zahn-Waxler, Cole, \& Barrett, 1991). In addition, girls also showed higher levels of verbal competence than did boys (i.e., there was a significant correlation between gender and MLU), and this verbal competency also may have contributed to their narrative proficiency and advanced levels of socioemotional development.

Unfortunately, because outcome assessments were taken at only one point in time, causal interpretations from the data must be made with caution. Nonetheless, because conflict assessments were taken prior to the development of many of the socioemotional and sociomoral skills assessed in this study, attributing the findings solely to prior individual differences in these skills seems unwarranted. Clearly more research is needed to confirm these findings, especially longitudinal studies that not only take multiple assessments of conflict across time, but also multiple outcome assessments. It is also important to note that the participants in this study consisted of predominantly White, middle-class mothers and children, and thus the results cannot be generalized to children from other cultures or economic groups. In fact, there is reason to suspect that there would be dramatic differences in the amount and nature of conflict based on culture. For example, White American and British communities emphasize a preference for agreement (but individuation) and the need for justification in opposition, whereas other cultures do not (Whiting \& Edwards, 1988).

In conclusion, the results from the present study suggest that differences in the frequency and nature of parent-toddler conflict relate to later individual differences in socioemotional and sociomoral development. Nonetheless, the results from this study are preliminary and much work still needs to be done to fully elucidate the relations among conflict elements and children's subsequent development, especially across different contexts. In addition, the results from this study suggest many rich untapped areas for future research. For instance, there was tremendous variation among the dyads in the amount of conflict observed (ranging between 5-51 conflict episodes per hour). It is not clear from this study what factors led 
to such dramatic differences in the amount of conflict observed in mother-child dyads, but potential factors include child temperament, attachment security, and parental acceptance of conflict. Finally, it is also important that researchers consider a more bidirectional approach when examining the influence of conflict on children's emotional development. It is likely that children not only create the contexts in which conflict occurs, by deciding which parental demands are resisted and negotiated, but it also seems likely that the strategies that children use in conflict influence the tactics that parents use in conflict (Kuczynski, Marshall, \& Schell, 1997).

\section{ACKNOWLEDGMENTS}

Support for this study was provided by a National Institute of Health Predoctoral National Research Service Award and an American Psychological Association Dissertation Award.

\section{AUTHOR ADDRESSES AND AFFILIATIONS}

Corresponding author: Deborah J. Laible, Department of Psychology, Southern Methodist University, Dallas, TX 75275-0442; e-mail: dlaible@mail.smu.edu. Ross A. Thompson is at the University of NebraskaLincoln.

\section{REFERENCES}

Bowlby, J. (1980). Attachment and loss: Vol. 3. Loss: sadness and depression. New York: Basic Books.

Bretherton, I. (1990). Open communication and internal working models: Their role in the development of attachment relations. In R. A. Thompson (Ed.), Socioemotional development. Nebraska Symposium on Motivation (Vol. 36, pp. 57-113). Lincoln: University of Nebraska Press.

Brown, J., \& Dunn, J. (1996). Continuities in emotional understanding from 3 to 6 years. Child Development, 67, 789-802.

Cicchetti, D., Cummings, E. M., Greenberg, M., \& Marvin, R. (1990). An organizational perspective on attachment beyond infancy. In M. Greenberg, D. Cicchetti, \& E. M. Cummings (Eds.), Attachment in the preschool years (pp. 3-49). Chicago: University of Chicago Press.

Denham, S. (1986). Social cognition, pro-social behavior, and emotion in preschoolers: Contextual validation. Child Development, 57, 194-201.

Denham, S., \& Auerbach, S. (1995). Mother-child dialogue about emotions and preschoolers' emotional competence. Genetic, Social, and Psychology Monographs, 121, 313-337.

Denham, S., Zoller, D., \& Couchoud, E. (1994). Socialization of preschoolers' emotion understanding. Developmental Psychology, 30, 928-936.
Dix, T. (1991). The affective organization of parenting: Adaptive and maladaptive processes. Psychological Bulletin, 110, 3-25.

Dunn, J. (1987). The beginnings of moral understanding: Development in the second year. In J. Kagan \& S. Lamb (Eds.), The emergence of morality in young children (pp. 91112). Chicago: University of Chicago Press.

Dunn, J. (1988). The beginnings of social understanding. Cambridge, MA: Harvard University Press.

Dunn, J., Brown, J., \& Beardsall, L. (1991). Family talk about feeling states and children's later understanding of others' emotions. Developmental Psychology, 27, 448-455.

Dunn, J., \& Munn, P. (1985). Becoming a family member: Family conflict and the development of social understanding in the second year. Child Development, 56, 480492.

Dunn, J., \& Munn, P. (1987). Development of justification in disputes with mother and sibling. Developmental Psychology, 23, 791-798.

Dunn, J., \& Slomkowski, C. (1992). Conflict and the development of social understanding. In C. Shantz \& W. Hartup (Eds.), Conflict in child and adolescent development (pp. 70-92). New York: Cambridge University Press.

Eisenberg, A. (1992). Conflicts between mothers and their young children. Merrill-Palmer Quarterly, 38, 21-43.

Fivush, R., \& Fromhoff, F. (1988). Style and structure in mother-child conversations about the past. Discourse Processes, 11, 337-355.

Grieshaber, S. (1997). Mealtime rituals: Power and resistance in the construction of mealtime rituals. British Journal of Sociology, 48, 649-666.

Hart, C., Ladd, G., \& Burleson, B. (1990). Children's expectations of the outcomes of social strategies: Relations with sociometric status and maternal disciplinary style. Child Development, 57, 202-216.

Hartup, W., \& Laursen, B. (1993). Conflict and context in peer relations. In C. Hart (Ed.), Children on playgrounds: Research perspectives and applications (pp. 44-84). Ithaca, NY: SUNY Press.

Hay, D. (1984). Social conflict in early childhood. In G. Whithurst (Ed.), Annals of child development (Vol. 1, pp. 144). Greenwich, CT: JAI Press.

Herrera, C., \& Dunn, J. (1997). Early experiences with family conflict: Implications for arguments with a close friend. Developmental Psychology, 33, 869-881.

Hoffman, M. (1983). Affective and cognitive processes in moral internalization. In E. T. Higgins, D. Ruble, \& W. Hartup (Eds.), Social cognition and social development: A sociocultural perspective (pp. 236-274). New York: Cambridge University Press.

Hoffman, M. (1984). Empathy, its limitations, and its role in a comprehensive moral theory. In W. Kurtines \& J. Gewirtz (Eds.), Morality, moral behavior, and moral development (pp. 283-302). New York: Wiley.

Howe, N. (1990). Socialization, perspective-taking, and the sibling relationship. Developmental Psychology, 26, 160165.

Hudson, J. (1990). The emergence of autobiographical memory in mother-child conversation. In R. Fivush \& 
J. Hudson (Eds.), Knowing and remembering in young children (pp. 166-196). New York: Cambridge University Press.

Klimes-Dougan, B., \& Kopp, C. (1991). Children's conflict tactics with mothers: A longitudinal investigation of the toddler and preschool years. Merrill Palmer Quarterly, 45, 226-242.

Kochanska, G. (1995). Children's temperament, mother's discipline, and security of attachment: Multiple pathways to emerging socialization. Child Development, 66, 597-613.

Kochanska, G., \& Aksan, N. (1995). Mother-child mutually positive affect, the quality of child compliance to requests and prohibitions, and maternal control as correlates of early internalization. Child Development, 66, 236-254.

Kochanska, G., Aksan, N., \& Koenig, A. (1995). A longitudinal study of the roots of preschoolers' conscience: Committed compliance and emerging internalization. Child Development, 66, 1752-1769.

Kuczynski, L., Kochanska, G., Radke-Yarrow, M., \& Girnius-Brown, O. (1987). A developmental interpretation of young children's noncompliance. Developmental Psychology, 23, 799-806.

Kuczynski, L., Marshall, S., \& Schell, K. (1997). Value socialization in a bidirectional context. In J. Grusec \& L. Kuczynski (Eds.), Parenting and children's internalization of values: A handbook of contemporary theory. New York: Wiley.

Laible, D., \& Thompson, R. (1998). Attachment and emotional understanding in preschool children. Developmental Psychology, 34, 1038-1045.

Laible, D., \& Thompson, R. (2000). Mother-child discourse, attachment security, shared positive affect, and early conscience development. Child Development, 71, 1424-1440.

Oppenheim, D., Emde, R., \& Warren, S. (1997). Children's narrative representations of mothers: Their development and associations with child and mother adaptation. Child Development, 68, 127-138.

Oppenheim, D., Nir, A., Warren, S., \& Emde, R. (1997). Emotion regulation in mother-child narrative co-constructions: Associations with children's narratives and adaptation. Developmental Psychology, 33, 284-294.
Perlman, M., \& Ross, H. (1997). The benefits of parent intervention in children's disputes: An examination of concurrent changes in children's fighting styles. Child Development, 68, 690-700.

Reese, E., Haden, C., \& Fivush, R. (1993). Mother-child conversations about the past: Relationships of style and memory over time. Cognitive Development, 8, 403-430.

Rogoff, B. (1990). Apprenticeship in thinking: Cognitive development in social context. New York: Oxford University Press.

Ross, H., Martin, J., Perlman, M., Smith, M., Blackmore, E., \& Hunter, J. (1996). Autonomy and authority in the resolution of sibling disputes. In M. Killen (Ed.), New directions for child development: No. 73. Children's autonomy, social competence, and interactions with adults and other children: Exploring connections and consequences (pp. 7190). San Francisco: Jossey-Bass.

Shatz, M., \& Gelman, R. (1973). The development of communication skills: Modifications in the speech of young children as a function of listener. Monographs of the Society for Research in Child Development, 38(5, Serial No. 152).

Thompson, R. (1998). Early sociopersonality development. In N. Eisenberg (Ed.), W. Damon (Series Ed.), Handbook of child psychology: Vol. 3. Social, emotional, and personality development (5th ed., pp. 25-104). New York: Wiley.

Vandell, D., \& Baily, M. (1992). Conflict between siblings. In C. Shantz \& W. Hartup (Eds.), Conflict in child and adolescent development (pp. 186-215) New York: Cambridge University Press.

Vygotsky, L. (1978). Mind in society. Cambridge, MA: Harvard University Press.

Whiting, B., \& Edwards, C. (1988). Children of different worlds. Cambridge, MA: Harvard University Press.

Zahn-Waxler, C., Cole, P., \& Barrett, K. (1991). Guilt and empathy: Sex differences and implications for the development of depression. In J. Garber \& K. Dodge (Eds.), The development of emotion regulation and dysregulation (pp. 243-272). Cambridge, U.K.: Cambridge University Press.

Zahn-Waxler, C., Radke-Yarrow, M., \& King, R. (1979). Child rearing and children's prosocial initiations towards victims of distress. Child Development, 50, 319-330. 
Copyright $\odot 2002$ EBSCO Publishing 